\title{
REGISTRO DE PLEURODEMA BUFONINUM BELL 1843 (AMPHIBIA: ANURA: LEIUPERIDAE) EN UNA TURBERA DE SPHAGNUM MAGELLANICUM BRID, PROVINCIA DE ÚLTIMA ESPERANZA, REGIÓN DE MAGALLANES
}

\author{
PRESENCE OF PLEURODEMA BUFONINUM BELL 1843 (AMPHIBIA: ANURA: LEIUPERIDAE) \\ IN A SPHAGNUM PEAT BOG, PROVINCE OF ÚLTIMA ESPERANZA, MAGALLANES
}

Nelson Bahamonde ${ }^{1}$.

En Chile hay 57 especies de batracios (uno introducido) todos anuros (Ortiz \& Díaz - Páez, 2006), distribuidos en cinco áreas biogeográficas con solo una especie para la Región Patagónica, $P$. bufoninum (Cei 1962). En Magallanes gran parte de la batracofauna se distribuye en los canales patagónicos, pero esta distribución presenta discordancias debido al escaso conocimiento disponible (Asencio et al. 2009).

$P$. bufoninum (Tabla 1) es un batracio de tamaño pequeño de piel lisa con pequeñas rugosidades. Posee una coloración dorsal gris oscuro, con manchas dorsales. Puede presentar estrías de coloración amarillo verdoso sobre el dorso y blanco grisáceo hacia el vientre. Posee glándulas lumbares alargadas y ovaladas en la parte posterior del cuerpo, de coloración grisácea mayores que las del sapito de cuatro ojos (Pleurodema thaul Lesson 1826). Extremidades cortas y finas. Dedos de patas traseras sin membrana interdigital. Tímpano visible externamente. De hábito nocturno, durante el día se refugia bajo rocas o en la vegetación circundante a los cursos de aguas. La ovipostura es en forma de racimo y es dejada en charcos temporales o lagunas poco profundas entre la vegetación acuática.
La larva es de vida libre y se desarrolla en aguas lénticas (Celis et al. 2011). Su dieta se compone de artrópodos (Formicidae), ninfas de hemípteros, ácaros y coleópteros, y una fracción de vegetales (Celis et al. 2011).

$P$. bufoninum frecuenta cuerpos de agua poco profundos y también ambientes marcadamente desertícolas (Pincheira, 2002). Es originaria de la Patagonia central (Ferraro, 2009) y es una especie compartida con Argentina (Ortiz \& Díaz - Páez, 2006), se encuentra en un amplio rango geográfico de Argentina y Chile, incluyendo la estepa patagónica, zonas de transición y bosques templados australes, con un rango altitudinal de 0 - 2.300 metros. Su distribución en Chile se extiende desde la Región

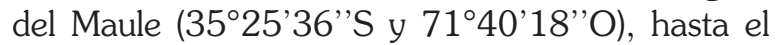
Parque Nacional Torres del Paine, en la Región de Magallanes y Antártica Chilena $51^{\circ} 2^{\prime} 0.77^{\prime \prime S}$ y 72³3'55.13"O (Celis et al. 2011). En Magallanes esta distribución no es definitiva debido al escaso conocimiento de las especies existentes y de su real distribución geográfica (Asencio et al. 2009).

El objetivo de esta nota es informar el hallazgo de la especie en una turbera fuera de los límites de su distribución actual informada.

\footnotetext{
${ }^{1}$ Laboratorio de Botánica, Instituto de la Patagonia, Universidad de Magallanes. nebahamo@umag.cl, Organización no gubernamental de desarrollo medioambiental AMA Torres del Paine, Estancia Cerro Paine S/N, Torres del Payne, Magallanes Chile.
} 


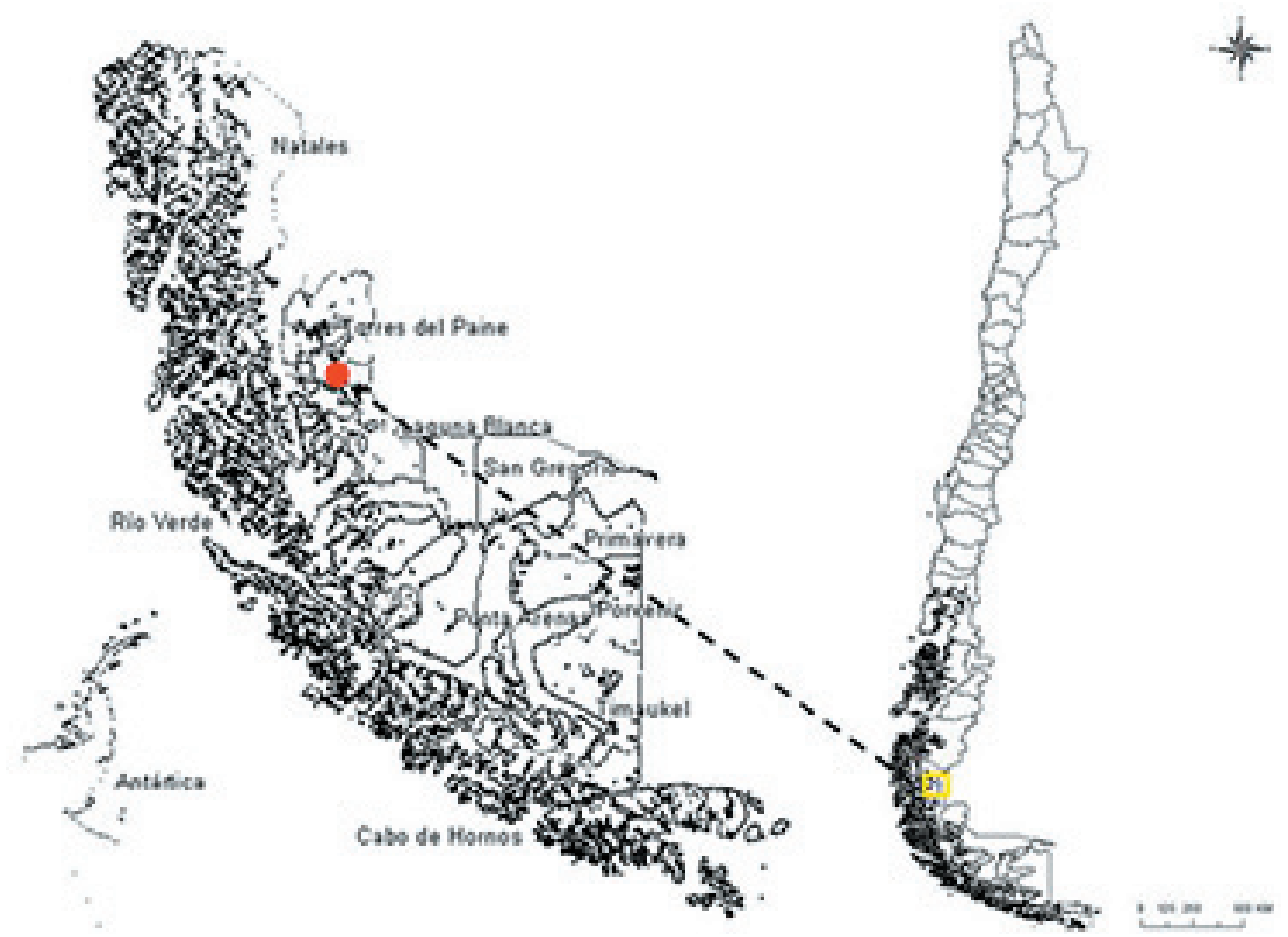

Fig. 1. Ubicación geográfica del área donde se muestran en círculos la ubicación de la turbera.
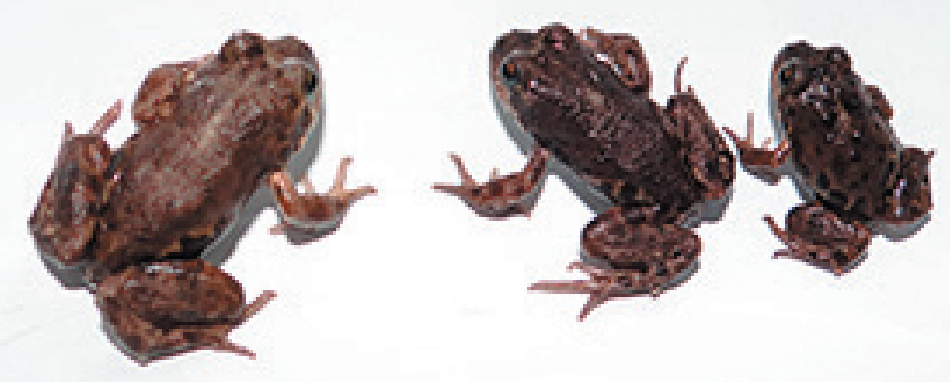

Fig. 2. Ejemplares capturados de Pleurodema Bufoninum. Referencia $3 \mathrm{~cm}$.

El muestreo que permitió encontrar a este anfibio en una turbera, se realizó en Febrero de 2013 aplicando el método de búsqueda de refugio (BR), registrando anfibios en todos los hábitats hídricos, bajo y entre la vegetación y restos de ésta en el suelo y el método de registro de encuentro visual caminando a lo largo de la turbera en zigzag, buscando anfibios a una distancia visual de entre 1 a 3 metros (Asencio et al. 2009).
El sito del hallazgo se ubica a $28 \mathrm{Km}$ al sur del Parque Nacional Torres del Paine (Fig.1), (51 $16^{\prime} 20.10^{\prime \prime}$ y y $72^{\circ} 51^{\prime} 56.30$ "O) y corresponde a una turbera de Spagnum magellanicum.

La identificación se basó en Ferraro (2009) y Celis et al. (2011). Las medidas se hicieron con pie de metro $(0,05 \mathrm{~mm})$ y balanza analítica AND HR-120 (Resolución 0.01mg).

De los tres ejemplares capturados 2 fueron 
ingresados a la sala de colecciones del Instituto de la Patagonia. Los individuos hallados transitaban en lagunillas con muy poca o nada de agua. Un cuarto ejemplar fue registrado visualmente en una lagunilla, donde se sumergió por debajo de la turba que cubría el fondo (profundidad $10 \mathrm{~cm}$ ).

Las medidas de largo cabeza-urostilo, pata trasera, pata delantera se muestran en la Tabla 1.

Tabla 1. Registro de las mediciones de los ejemplares capturados de Pleurodema Bufoninum.

\begin{tabular}{lccc}
\hline Medidas & $\mathrm{N}^{\circ} \mathrm{CZIP}$ & $\mathrm{N}^{\circ} \mathrm{CZIP}$ & $\mathrm{N}^{\circ} \mathrm{CZIP}$ \\
\hline Cabeza Urostilo & 56 & 57 & \\
Pata Trasera & $22,3 \mathrm{~mm}$ & $17,7 \mathrm{~mm}$ & $24,6 \mathrm{~mm}$ \\
Pata delantera & $29,8 \mathrm{~mm}$ & $22,8 \mathrm{~mm}$ & $32,6 \mathrm{~mm}$ \\
Peso & $12 \mathrm{~mm}$ & $10,2 \mathrm{~mm}$ & $12,1 \mathrm{~mm}$ \\
\hline
\end{tabular}

CZIP = Colección zoológica Instituto de la Patagonía

Este registro al sur del parque Torres del Paine podría constituir un antecedente que amplie el rango de distribución de la especie, estableciendo una tendencia a la continuidad de la distribución hacia la zona del Seno Obstrucción en la provincia de Ultima Esperanza. Esto podría ser posible ya que los sistemas de turberas si presentan un continuo en las áreas ubicadas al oeste de la Región de Magallanes (Kleinebecker 2007, Pisano 1983), además de existir registros de otros anuros asociados a turberas (Díaz -Páez et al. 2002). Este registro constituye un antecedente más que complementa la información sobre la distribución de $P$. bufoninum en áreas donde no ha sido registrada y contribuye a la escasa información que existe respecto a la batraco fauna de Chile y la fauna de turberas.

\section{AGADECIMIENTOS}

Se agradece al programa "Bases ambientales, jurídicas y comerciales para el desarrollo sustentable de las turberas de Magallanes" que es financiado por el Gobierno Regional de Magallanes, así como la SEREMI de Agricultura de la Región de Magallanes y al Instituto de Investigaciones Agropecuarias. También se agradece el aporte en la identificación de
Jessica Asencio, Bióloga mención medio ambiente, colaboración en el muestreo de Carlos Cárdenas estudiante de Biología Marina de la Universidad de Magallanes y la revisión del escrito por parte de Paola Arroyo Vargas estudiante de Ingeniería en Recursos Naturales Renovables, Universidad Católica de Temuco.

\section{LITERATURA CITADA}

Asencio, J., A. Kusch, M. Henríquez \& J. Cárcamo (2009). Registros de anfibios en el bosque norpatagónico costero del canal Messier, Chile. Anales Instituto Patagonia (Chile) 37(1):113-116.

Cei, J. M. (1962). Batracios de Chile. Ediciones de la Universidad de Chile, Santiago.

Celis, J., S. Ippi, A. Charrier \& C. Garín. Guía de campo de los vertebrados terrestres, Fauna de los Bosques Templados de Chile. Ed. Corporación Chilena de la Madera, Concepción, Chile.

Díaz-Páez, H. \& J. C. Ortiz (2003). Evaluación del estado de conservación de los anfibios en Chile. Revista Chilena de Historia Natural 76: 509 - 525

Ferraro, D. (2009). Relaciones filogenéticas y biogeografícas de las especies del género Pleurodema (Amphibia: Anura: Leiuperidae). Tesis doctoral, Facultad de Ciencias Naturales y Museo Universidad Nacional de La Plata, Argentina.

Kleinebecker, T., N. Hölzel \& A. Vogel (2007). Gradients of Continentality and moisture in south Patagonian ombrotrophic peatland vegetation, Folia Geobotanica 42:363-382.

Ortiz, J. C. \& H. Díaz - Páez (2006). Estado de conocimiento de los anfibios de Chile. Gayana (Concepción) 70: 114 - 121.

Pincheira, D. (2002). Nota sobre la alimentación de Pleurodema bufonina Bell, 1843 (anura -leptodactylidae). Gayana (Concepc.), 66(1): 77-80 
